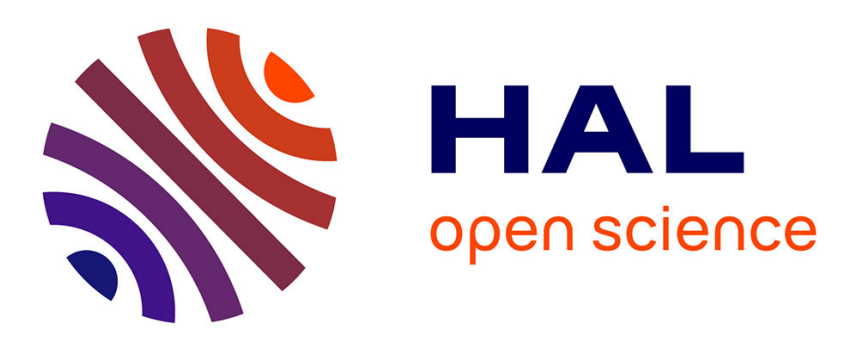

\title{
Impact of Convective Organization on the Response of Tropical Precipitation Extremes to Warming
}

Caroline Muller

\section{To cite this version:}

Caroline Muller. Impact of Convective Organization on the Response of Tropical Precipitation Extremes to Warming. Journal of Climate, 2013, 26 (14), pp.5028-5043. 10.1175/jcli-d-12-00655.1 . hal-00995152

HAL Id: hal-00995152

https://hal-polytechnique.archives-ouvertes.fr/hal-00995152

Submitted on 27 May 2014

HAL is a multi-disciplinary open access archive for the deposit and dissemination of scientific research documents, whether they are published or not. The documents may come from teaching and research institutions in France or abroad, or from public or private research centers.
L'archive ouverte pluridisciplinaire HAL, est destinée au dépôt et à la diffusion de documents scientifiques de niveau recherche, publiés ou non, émanant des établissements d'enseignement et de recherche français ou étrangers, des laboratoires publics ou privés. 


\title{
Impact of Convective Organization on the Response of Tropical Precipitation Extremes to Warming
}

\author{
CAROLine Muller \\ Atmospheric and Oceanic Sciences Program, Princeton University, Princeton, New Jersey, and Laboratoire \\ d'Hydrodynamique (LadHyX), CNRS-École Polytechnique, Palaiseau, France
}

(Manuscript received 15 September 2012, in final form 7 January 2013)

\begin{abstract}
In this study the response of tropical precipitation extremes to warming in organized convection is examined using a cloud-resolving model. Vertical shear is imposed to organize the convection into squall lines. Earlier studies show that in disorganized convection, the fractional increase of precipitation extremes is similar to that of surface water vapor, which is substantially smaller than the increase in column water vapor. It has been suggested that organized convection could lead to stronger amplifications.

Regardless of the strength of the shear, amplifications of precipitation extremes in the cloud-resolving simulations are comparable to those of surface water vapor and are substantially less than increases in column water vapor. The results without shear and with critical shear, for which the squall lines are perpendicular to the shear, are surprisingly similar with a fractional rate of increase of precipitation extremes slightly smaller than that of surface water vapor. Interestingly, the dependence on shear is nonmonotonic, and stronger supercritical shear yields larger rates, close to or slightly larger than surface humidity.

A scaling is used to evaluate the thermodynamic and dynamic contributions to precipitation extreme changes. To first order, they are dominated by the thermodynamic component, which has the same magnitude for all shears, close to the change in surface water vapor. The dynamic contribution plays a secondary role and tends to weaken extremes without shear and with critical shear, while it strengthens extremes with supercritical shear. These different dynamic contributions for different shears are due to different responses of convective mass fluxes in individual updrafts to warming.
\end{abstract}

\section{Introduction}

The response of the hydrological cycle to climate change has many societal impacts. Both changes in mean precipitation and in precipitation extremes are expected with an increase in surface temperatures. It is well known that the change in global mean precipitation is constrained by energetics (Allen and Ingram 2002; Held and Soden 2006; Muller and O'Gorman 2011). Specifically, the changes in latent heat from precipitation and in surface sensible heat flux have to balance the change in atmospheric radiative cooling [rhs (1)]. This energetic constraint limits the increase of global mean precipitation to a rate of about $2 \% \mathrm{~K}^{-1}$ in simulations of twenty-first-century climate change (Held and Soden 2006), much lower than the increase in the availability

Corresponding author address: Caroline Muller, Laboratoire d'Hydrodynamique (LadHyX), CNRS-École Polytechnique, 91128 Palaiseau CEDEX, France.

E-mail: carolinemuller123@gmail.com of moisture in a warmer climate, from $6 \%$ to $12 \% \mathrm{~K}^{-1}$ depending on latitude (O'Gorman and Muller 2010). Given the small changes in model relative humidity (Soden and Held 2006), the atmospheric humidity is expected to increase according to the Clausius-Clapeyron (CC) equation, which predicts an approximately exponential increase with temperature. An increase in atmospheric specific humidity has already been observed in recent years (Trenberth 2011). Over oceans, the increases are consistent with CC expectations with a constant relative humidity, while increases are somewhat lower over land especially where water availability is limited.

Changes in regional precipitation or in precipitation extremes, on the other hand, need not be constrained by global mean energetics. For the former, Muller and O'Gorman (2011) find that in simulations of twentyfirst-century climate change, changes in radiative and surface sensible heat fluxes are a guide to the regional precipitation response over land and at large scales (thousands of kilometers), but not at small scales over the ocean. For precipitation extremes, it has been 
argued that the heaviest rainfall events occur when effectively all of the moisture in a volume of air is precipitated out (Trenberth 1999; Allen and Ingram 2002; Pall et al. 2007). This implies that the rate of increase of precipitation extremes should follow the increase in atmospheric humidity, and could be even larger if vertical mass fluxes in convective updrafts were to increase. In the mean, the upward mass flux from tropical convection decreases with increasing temperatures (Betts 1998; Held and Soden 2006; Vecchi and Soden 2007), but the response in the individual convective towers leading to the heaviest rainfall rates could be different.

In observations of present-day variability, precipitation extremes have been found to increase at a greater fractional rate than the amount of atmospheric water vapor (Allan and Soden 2008; Lenderink and van Meijgaard 2008; Liu et al. 2009; Lenderink et al. 2011). Although present-day variability may not be directly relevant to global warming, this raises the possibility that tropical precipitation extremes could increase faster than CC expectations. Results from climate change simulations in general circulation models (GCMs) give widely divergent changes in precipitation extremes in the tropics (Emori and Brown 2005; O'Gorman and Schneider 2009; Sugiyama et al. 2010). For example, O'Gorman and Schneider find that the rate of increase of tropical precipitation extremes in the third Coupled Model Intercomparison Project (CMIP3) climate model simulations ranged from $1.3 \%$ to $30 \%$ depending on the climate model. The inability of current climate models to consistently predict changes in tropical precipitation extremes with warming is likely tied to the use of convective parameterizations (Wilcox and Donner 2007), and is not surprising given the failure of the climate models to simulate observed tropical precipitation extremes in the present climate (Kharin et al. 2007).

This motivates the use of high-resolution cloudresolving models (CRMs) to address this issue. Because of their large computational costs, such models are typically run in idealized settings (e.g., on square, doubly periodic domains over ocean with simplified microphysics), but they have the advantage that they resolve the convective-scale processes instead of parameterizing them. Recently, Romps (2011) and Muller et al. (2011, hereafter MOB11) used CRMs to investigate the response of precipitation extremes to warming in radiativeconvective equilibrium over ocean in the absence of convective organization. Despite some important differences in the settings (different CRMs, small versus large domain, fine versus coarse resolution, different sea surface temperature increases, interactive versus fixed radiative cooling rates), their conclusions are the same: the amplification of precipitation extremes with warming follows the increase in cloud-base water vapor, or surface Clausius-Clapeyron scaling $\left(\mathrm{CC}_{\mathrm{sfc}}\right)$, which is smaller than the increase in vertically integrated atmospheric humidity, or Clausius-Clapeyron scaling (CC). In the tropics, using column water vapor as a proxy for the rate of change of precipitation extremes instead of surface humidity can lead to substantial overestimates. O'Gorman and Muller (2010) find that, for climate model simulations of the Intergovernmental Panel on Climate Change Special Report on Emissions Scenarios A1B emissions scenario, the multimodel mean rate of increase in zonal mean column water vapor is $8.4 \%$ at the equator, whereas the increase in surface specific humidity is only $5.8 \%$, yielding an overestimate of about $45 \%$. Both CRM studies find that the increased SSTs yield an upward shift of atmospheric variables, consistent with the upward shift of the temperature profile on a warmer moist adiabat (Singh and O'Gorman 2012). They also find stronger vertical velocities in updrafts, though as pointed out in MOB11, the increase in vertical velocity $w$ does not necessarily imply an increase in vertical mass flux $\rho w$. The latter is more relevant to precipitation extremes.

The above results were derived in disorganized convection. Nevertheless, convective organization can strongly impact the distribution of precipitation and convective properties, and a large fraction of precipitation extremes occurs in organized convection. Various mechanisms can generate and modulate convective organization, such as internal feedbacks involving water vapor (Held et al. 1993; Tompkins 2001) or radiation (Bretherton et al. 2005; Stephens et al. 2008; Muller and Held 2012), as well as external forcings such as background vertical shear (Rotunno et al. 1988; Fovell and Ogura 1988; Garner and Thorpe 1992; Weisman and Rotunno 2004; Robe and Emanuel 2001). The ubiquity of convective organization above tropical oceans has been pointed out in several observational studies (Houze and Betts 1981; WCRP 1999; Nesbitt et al. 2000).

Recent results from Singleton and Toumi (2013) indicate that changes in precipitation extremes could be significantly larger when the convection is organized. Using a high-resolution CRM to study the response of precipitation extremes to warming in an idealized squall line, they find precipitation extremes changes in excess of CC (at surface temperatures higher than $24^{\circ} \mathrm{C}$ ), due to stronger vertical mass fluxes with warming. Though this study raises the possibility that organized convection could yield stronger amplifications of extremes, the warming in this case was done by warming the atmosphere by $1^{\circ} \mathrm{C}$ uniformly in the vertical. A uniform vertical warming increases the atmospheric instability. Indeed, 
the change of temperature consistent with a warmer moist adiabat, as is expected in response to an SST increase in the tropics, yields stronger warming aloft than at low levels. The increased atmospheric instability with uniform vertical warming could potentially overestimate the increase in vertical velocities and mass fluxes and, hence, the amplification of precipitation extremes.

The goal of this paper is to investigate the response of precipitation extremes to an SST increase in a CRM with organized convection. Background vertical shear is used to organize the convection into squall lines. The shear is maintained throughout the simulations, which are run to radiative convective equilibrium. Once equilibrium is reached, we start our analysis. Note that this is a slightly different setting than used by Singleton and Toumi (2013), who fix the background state and let the squall line propagate through this imposed background state. In our simulations, on the other hand, the squall line is in equilibrium with the mean state. Although our setting is idealized (square, doubly periodic domain over ocean, no large-scale forcing, no orography), it can help shed some light on the impact of convective organization on the amplification of precipitation extremes with warming, and the methodology developed should also be applicable to less idealized simulations. Of particular interest are the following questions.

- Without convective organization, it was found in cloudresolving simulations that the fractional increase in precipitation extremes was substantially smaller than that in atmospheric water vapor, and was closer to the increase in surface water vapor concentrations. Does this result still hold in organized convection or does convective organization yield stronger amplifications of precipitation extremes with warming?

- Is the response of precipitation extremes to warming monotonic in the strength of the background vertical shear applied? In other words, does stronger shear yield larger amplifications?

- Can we use the framework introduced in MOB11 to investigate the thermodynamic and dynamic contributions to changes in precipitation extremes with warming? Can it help explain the sensitivity to shear?

The next section describes the numerical experiments, which are also listed in Table 1 . Section 3 examines the response of mean precipitation to warming for different shear values. Section 4 describes the response of precipitation extremes, which are analyzed further in section 5 using an approximate scaling for precipitation extremes. Conclusions are offered in section 6 .
TABLE 1. Description of the numerical simulations for the three cases: CTRL, SMLDMN, LOWRES. The profiles of the various shears (zero shear $=$ Shear0, critical shear $=$ Shear1, and supercritical shear $=$ Shear2) are shown in Fig. 2 . Each case and shear is run twice, first with $\mathrm{SST}=300 \mathrm{~K}$, then with $\mathrm{SST}=302 \mathrm{~K}$.

\begin{tabular}{|c|c|c|}
\hline Shear & SST $(\mathrm{K})$ & Description \\
\hline \multirow{3}{*}{ Shear0 } & & CTRL \\
\hline & 300 & $\begin{array}{l}\text { Control run (resolution of } 1 \mathrm{~km} \text {, domain } \\
\text { size of } 256 \mathrm{~km} \text { ) without shear and with } \\
\text { SST }=300 \mathrm{~K}\end{array}$ \\
\hline & 302 & Same as above but with SST $=302 \mathrm{~K}$ \\
\hline \multirow[t]{2}{*}{ Shear1 } & 300 & $\begin{array}{l}\text { Control run with critical shear and } \\
\text { SST }=300 \mathrm{~K}\end{array}$ \\
\hline & 302 & Same as above but with SST $=302 \mathrm{~K}$ \\
\hline \multirow[t]{2}{*}{ Shear2 } & 300 & $\begin{array}{l}\text { Control run with supercritical shear } \\
\text { and SST }=300 \mathrm{~K}\end{array}$ \\
\hline & 302 & Same as above but with SST $=302 \mathrm{~K}$ \\
\hline \multirow{3}{*}{ Shear0 } & & SMLDMN \\
\hline & 300 & $\begin{array}{l}\text { Small domain run (resolution of } 1 \mathrm{~km} \text {, } \\
\text { domain size of } 128 \mathrm{~km} \text { ) without shear } \\
\text { and with SST }=300 \mathrm{~K}\end{array}$ \\
\hline & 302 & Same as above but with SST $=302 \mathrm{~K}$ \\
\hline \multirow[t]{2}{*}{ Shear1 } & 300 & $\begin{array}{l}\text { Small domain run with critical shear } \\
\text { and SST }=300 \mathrm{~K}\end{array}$ \\
\hline & 302 & Same as above but with SST $=302 \mathrm{~K}$ \\
\hline \multirow[t]{2}{*}{ Shear2 } & 300 & $\begin{array}{l}\text { Small domain run with supercritical shear } \\
\text { and SST }=300 \mathrm{~K}\end{array}$ \\
\hline & 302 & Same as above but with SST $=302 \mathrm{~K}$ \\
\hline \multirow{3}{*}{ Shear0 } & & LOWRES \\
\hline & 300 & $\begin{array}{l}\text { Coarse-resolution run (resolution of } \\
2 \mathrm{~km} \text {, domain size of } 256 \mathrm{~km} \text { ) without } \\
\text { shear and with SST }=300 \mathrm{~K}\end{array}$ \\
\hline & 302 & Same as above but with SST $=302 \mathrm{~K}$ \\
\hline Shear1 & 300 & $\begin{array}{l}\text { Coarse-resolution run with critical shear } \\
\text { and SST }=300 \mathrm{~K}\end{array}$ \\
\hline \multirow{3}{*}{ Shear2 } & 302 & Same as above but with SST $=302 \mathrm{~K}$ \\
\hline & 300 & $\begin{array}{l}\text { Coarse-resolution run with supercritical } \\
\text { shear and SST }=300 \mathrm{~K}\end{array}$ \\
\hline & 302 & Same as above but with SST $=302 \mathrm{~K}$ \\
\hline
\end{tabular}

\section{Numerical simulations}

The CRM used in this study is the System for Atmospheric Modeling (SAM) version 6.6; see Khairoutdinov and Randall (2003) for a full description. The model solves the anelastic continuity, momentum, and tracer conservation equations. The prognostic thermodynamic variables of the model include total nonprecipitating water (vapor + cloud water + cloud ice) and total precipitating water (rain + snow + graupel). The mixing ratio of cloud water, cloud ice, rain, graupel, and snow is diagnosed from the prognostic variables using a temperature-dependent partition between liquid and ice phases. The frozen moist static energy, which is the sum of the liquid/ice water static energy and the total condensate amount times the latent heat of vaporization, is 
conserved during moist adiabatic processes in the model, including the freezing and melting of precipitation. The model is run to radiative convective equilibrium, and once equilibrium is reached the precipitation extremes are analyzed.

All simulations are three-dimensional on a square, doubly periodic horizontal domain. The vertical grid has 64 levels (capped at $27 \mathrm{~km}$ with a rigid lid), with the first level at $37.5 \mathrm{~m}$ and grid spacing gradually increasing from $80 \mathrm{~m}$ near the surface to $400 \mathrm{~m}$ above $5 \mathrm{~km}$, and a variable time step (10 s or less to satisfy the CourantFriedrichs-Lewy condition). The surface fluxes are computed using Monin-Obukhov similarity. To reduce gravity wave reflection and buildup, Newtonian damping is applied to all prognostic variables in the upper third of the model domain. We run three cases: the control case (CTRL) with resolution $d x=1 \mathrm{~km}$ and domain size $L=$ $256 \mathrm{~km}$, the small-domain case (SMLDMN) with the same resolution as CTRL but a smaller domain size $L=128 \mathrm{~km}$, and the low-resolution case (LOWRES) with the same domain size as CTRL but a coarser resolution $d x=2 \mathrm{~km}$ (see Table 1 for a summary of the various simulations).

For all three cases, we perform two experiments: a cold experiment with a SST of $300 \mathrm{~K}$ and a warm experiment with an SST of $302 \mathrm{~K}$. The radiative cooling rates are fixed for convenience (lower computational costs) and because we empirically found it easier to generate squall lines with fixed radiative cooling rates in this model. MOB11 showed that it is important to allow the radiative cooling profile to change according to the SST in warming experiments. This is because all vertical profiles shift upward following the warmer moist adiabat, and the radiative cooling profile needs to shift upward accordingly. Otherwise, the detrainment level is too low in the warm experiment (Hartmann and Larson 2002), and one obtains unrealistic decreases in condensate amounts and increases in precipitation efficiency. Therefore, we use different radiative cooling profiles in the cold and warm experiments (whose profiles are given in Fig. 1), which are obtained from a smaller domain run with interactive radiation and with the corresponding SSTs.

Vertical shear is imposed to organize the convection into squall lines. It is well known that in the presence of vertical wind shear, convection organizes into arcs. This organization follows from the fact that the background shear opposes the displacement of the cold pool and associated gust front relative to the free convection (e.g., Rotunno et al. 1988; Fovell and Ogura 1988; Garner and Thorpe 1992; Weisman and Rotunno 2004; Houze 2004; Moncrieff 2010). Three shear profiles are used: zero shear (Shear0), critical shear (Shear1), and supercritical shear

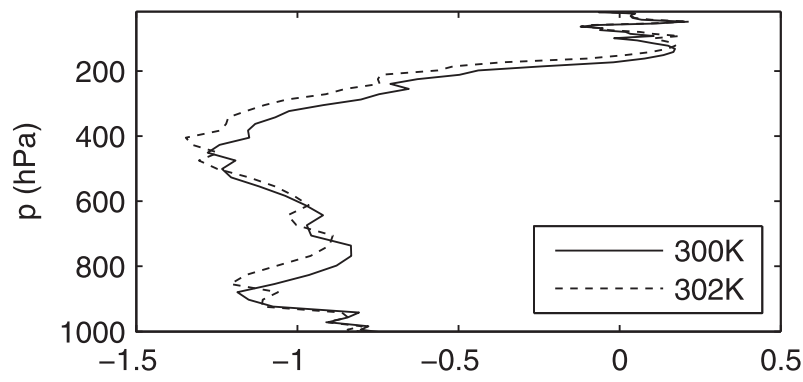

FIG. 1. Radiative cooling profiles $\left(\mathrm{K} \mathrm{day}^{-1}\right)$ used in the cold $(\mathrm{SST}=300 \mathrm{~K})$ and warm $(\mathrm{SST}=302 \mathrm{~K})$ simulations. The vertically integrated net atmospheric cooling increases from 94 to $101 \mathrm{~W} \mathrm{~m}^{-1}$ with warming, yielding a $3.7 \% \mathrm{~K}^{-1}$ increase.

(Shear2). The shear profiles are shown in the left panels of Fig. 2. The mean wind is relaxed over a time scale of $2 \mathrm{~h}$ toward these wind profiles. The critical shear corresponds to squall lines perpendicular to the shear (the shear is in the $x$ direction in all of our simulations), and is empirically determined to decrease from $U=10 \mathrm{~m} \mathrm{~s}^{-1}$ at the surface to $U=0 \mathrm{~m} \mathrm{~s}^{-1}$ at $1 \mathrm{~km}$. The supercritical shear, which is obtained by doubling the critical shear, yields squall lines oriented at an angle of about $45^{\circ}$ with respect to the shear, so the projection of the shear onto the squall line is critical (see, e.g., Robe and Emanuel 2001). The critical shear that we use is somewhat weaker and shallower than the shear used in Singleton and Toumi (2013) whose vertical wind profile decreases from 12 to $0 \mathrm{~m} \mathrm{~s}^{-1}$ in the lowest $2.5 \mathrm{~km}$ of the atmosphere. The right panels in Fig. 2 show snapshots of clouds in the CTRL case with the three different shear profiles.

The organization looks similar in all three cases (CTRL, SMLDMN, and LOWRES), as can be seen in Figs. 3-5, which show time series of instantaneous vertically integrated atmospheric water vapor in all cases without shear, with critical shear and with supercritical shear, respectively. Without shear (Fig. 3), convection is disorganized. Individual convective events occur somewhat randomly throughout the domain and typically last a few hours (the snapshots in Fig. 3 are separated by an hour). With critical shear (Fig. 4), the simulation looks quite different. All convection is aligned along a squall line perpendicular to the shear, and the convecting arc is very steady in time (the snapshots in Fig. 4 are separated by a day and a half). With supercritical shear (Fig. 5), the convecting arc is oriented at an angle of about $45^{\circ}$, so that the cross-arc component of shear is near its critical value. The arcs are slowly advected downshear (the snapshots in Fig. 5 are separated by $5 \mathrm{~h}$ ), at a rate of about $2 \mathrm{~m} \mathrm{~s}^{-1}$, which is much slower than the surface background velocity $\left(20 \mathrm{~m} \mathrm{~s}^{-1}\right)$.

Table 1 summarizes the various simulations. We now investigate the change in the distribution of precipitation, 

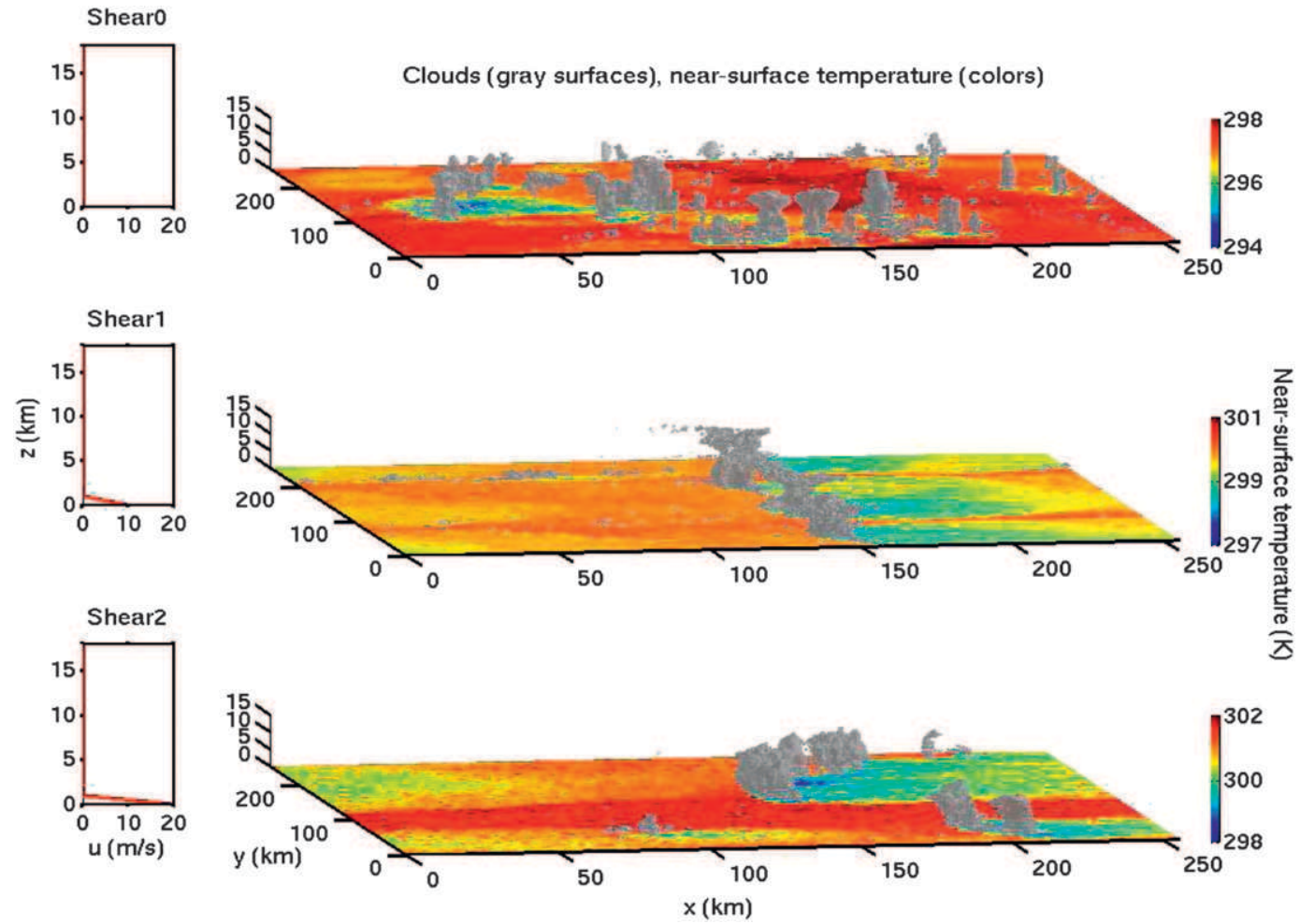

FIG. 2. Snapshots of clouds (gray surfaces) and near-surface temperatures (first model level $z=37.5 \mathrm{~m}$ ) in the CTRL runs with SST $=300 \mathrm{~K}$ (i.e., cold runs; the warm runs have similar organization) for (left) three shear profiles: (top) without shear, convection is not organized and resembles "popcorn" convection; (middle) with critical shear (decreasing linearly from $10 \mathrm{~m} \mathrm{~s}^{-1}$ at the surface to 0 at $1 \mathrm{~km}$ ), the convection organizes into a squall line perpendicular to the shear (the shear is in the $x$ direction); and (bottom) with supercritical shear (twice the critical shear), the arcs are oriented at an angle of about $45^{\circ}$ so that the projected shear is critical.

both mean and extremes, between the cold run and the warm run in the various cases for different shears.

\section{Results: Mean precipitation}

The time and space mean precipitation satisfies the mean energy budget of the atmosphere:

$$
L_{v}\langle P\rangle+\langle S\rangle \approx\left\langle Q_{\mathrm{rad}}\right\rangle,
$$

where $L_{v} P$ is the latent heat associated with the surface precipitation $P, S$ is the surface sensible heat flux, and $Q_{\text {rad }}$ the vertically integrated radiative cooling; the angle brackets denote the time and space average. Since we use fixed radiative cooling rates, the change in radiative cooling is the same in all cases and for all shears. Therefore, we expect the change in mean precipitation to be similar in all the runs modulo some small changes in $S$. We see that this is indeed the case: Fig. 6 shows the changes in mean precipitation, precipitation intensity (defined as the precipitation averaged over points with nonzero precipitation), precipitation frequency (frequency of occurrence of nonzero precipitation), precipitable water, and near-surface specific humidity (at the first model level $z=37.5 \mathrm{~m}$ ). The change in surface water vapor is always smaller than the change in atmospheric water vapor for two reasons: 1) on a warmer moist adiabat, the warming is stronger aloft than at low levels and 2) the fractional rate of increase as predicted by the Clausius-Clapeyron equation at fixed relative humidity depends on temperature and increases at lower temperatures, hence at higher altitudes.

The changes in mean precipitation are approximately the same in all cases, consistent with the energetic constraint and the observed small changes in surface sensible heat flux (not shown). More importantly, changes in mean precipitation are smaller than the increase in atmospheric moisture, or CC scaling. This is consistent with the fact that mean precipitation is determined by energetics, not by local thermodynamics, as was already pointed out in earlier studies (MOB11; Romps 2011). The changes in precipitation intensity are also smaller than $\mathrm{CC}$, and generally even smaller than $\mathrm{CC}_{\text {sfc }}$, except with the strongest shear at low resolution. In that case, 


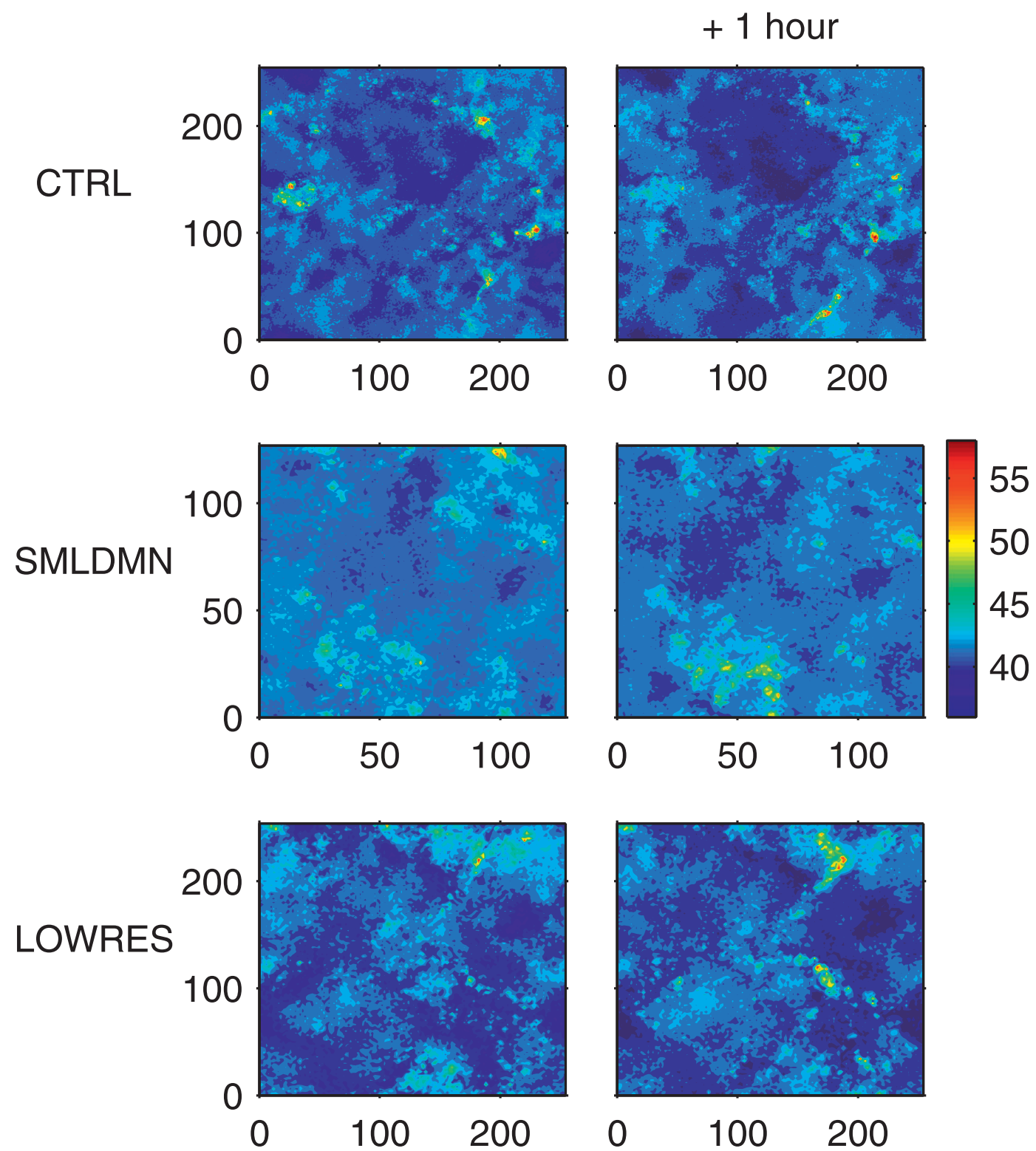

FIG. 3. Instantaneous precipitable water $\left(\mathrm{kg} \mathrm{m}^{-2}\right)$ in the runs without shear and with $\mathrm{SST}=300 \mathrm{~K}$ (the warm runs have similar organization) for the (top) the control run (CTRL), (middle) small domain run (SMLDMN), and (bottom) the coarse resolution run (LOWRES); see Table 1 for a description of the runs. Without shear, the convection is disorganized. The snapshots on the left and right are separated by $1 \mathrm{~h}$.

the precipitation frequency decreases significantly $\left(-3.4 \% \mathrm{~K}^{-1}\right)$, which allows for a larger increase in precipitation intensity (keeping the change in mean precipitation fixed). The decrease in precipitation frequency with supercritical shear is robust throughout all cases, but the strongest decrease at low resolution might be an artifact of the coarse resolution.

The small increases in precipitation intensity in our simulations are at odds with results from Singleton and Toumi (2013), who find a $1.5 \times$ CC increase in storm-averaged rainfall. This might be the consequence of the uniform vertical warming that they use, which increases the atmospheric instability and hence likely overestimates vertical velocities in updrafts.

\section{Results: Precipitation extremes}

We now investigate the change in the distribution of hourly mean pointwise precipitation, with particular 


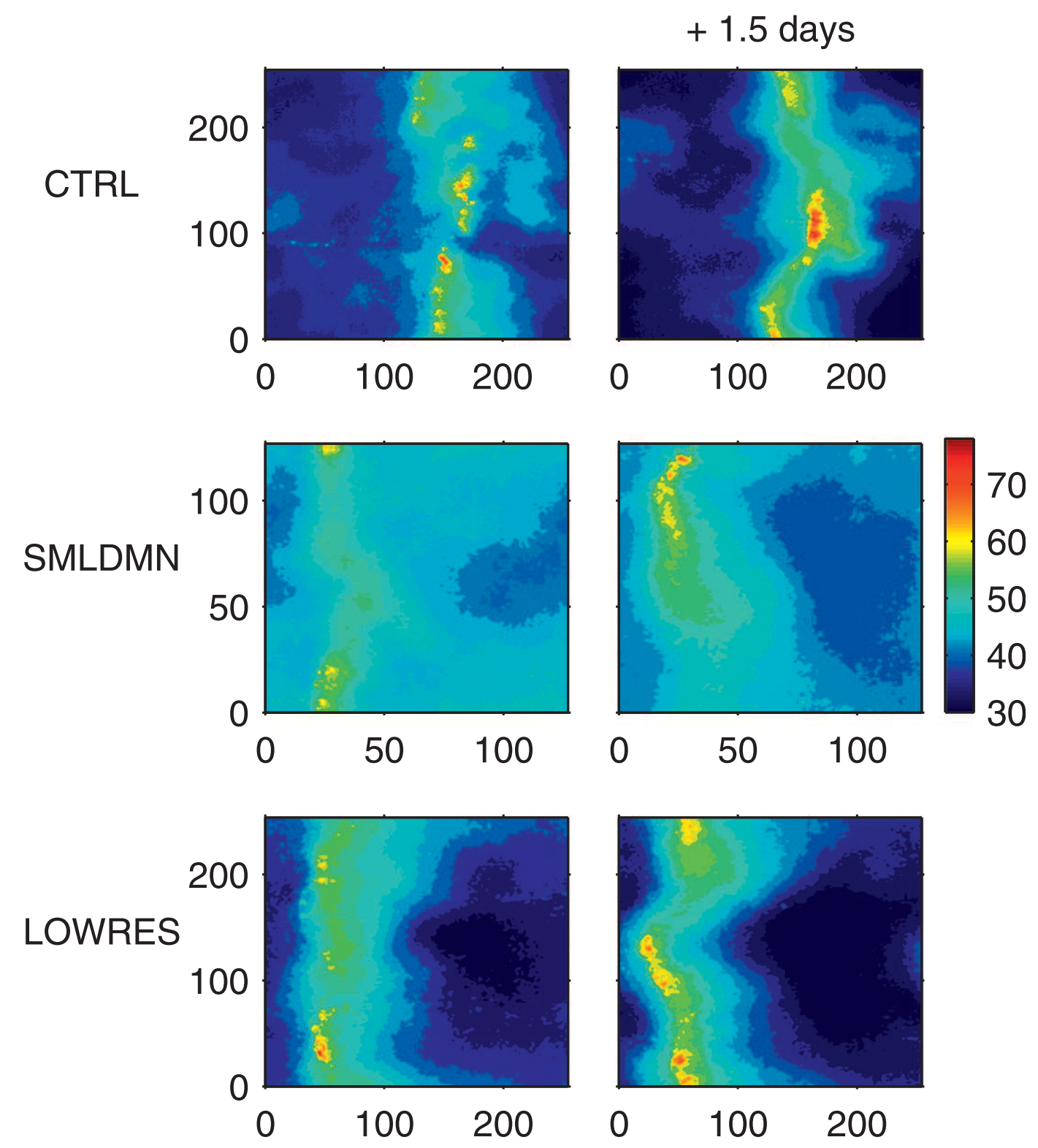

FIG. 4. As in Fig. 3 but with critical shear and with snapshots separated by $1 \frac{1}{2}$ days. With critical shear the convection is organized along arcs perpendicular to the shear.

emphasis on the change in its extremes. The extremes are computed over all times and all points in space. We checked the convergence of the precipitation extremes in our simulations by splitting the time series in two and comparing the extremes obtained in the two subsamples. We find that the convergence of extremes is much faster (typically a few days) without shear than with shear (tens of days), probably due to more internal variability with shear. Our analysis therefore required long simulations, 40 days in CTRL and 52 days in SMLDMN and LOWRES (the convergence is slightly faster in CTRL, which has the largest number of points).
To initiate our study of precipitation extremes, we compute the distribution of precipitation in the control case. Figure 7 shows the distribution of precipitation with the various shears in the cold simulations (SST = $300 \mathrm{~K}$; the warm simulations look similar). In the presence of shear, low precipitation rates become less frequent while high precipitation rates become more frequent. Interestingly, adding a background vertical shear strongly impacts the distribution of precipitation, but the value of the shear, critical or supercritical, has little impact. This is also true for precipitation extremes, as can be seen in the top panel of Fig. 8, which shows the high percentiles of 


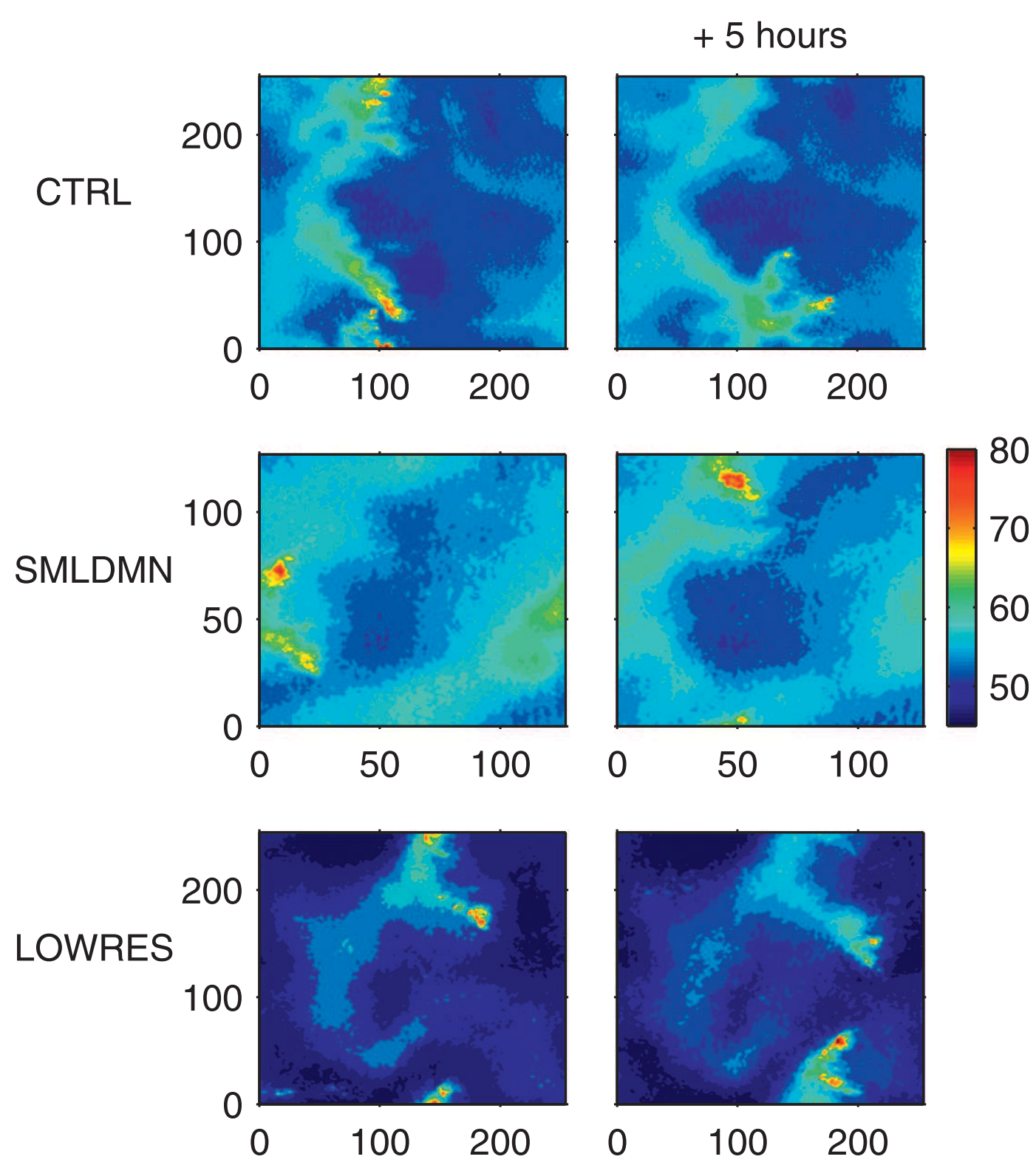

FIG. 5. As in Fig. 3 but with supercritical shear and with snapshots separated by $5 \mathrm{~h}$. With supercritical shear the convection is organized along arcs oriented at an angle of about $45^{\circ}$ with the shear.

precipitation with the various shears in the cold and warm simulations. We see that precipitation extremes are sensitive to vertical shear and almost double in the presence of shear, but increasing the shear from critical to supercritical shear has very little effect on the rainfall rates. This is a robust result throughout all of our cases (not shown). This may not be too surprising since in the supercritical case the squall lines orient themselves so that the line-perpendicular component of the shear is critical. Therefore, one would expect rainfall rates similar to the ones obtained with critical shear as long as the shear is above critical. We performed an additional simulation for which the shear is half its critical value; in that case, the precipitation statistics are halfway between zero and critical shear as expected (not shown).

We also see from Fig. 8 that warming yields larger precipitation rates at the highest percentiles. This is even clearer in the bottom panel of Fig. 8, which shows the fractional increase in precipitation extremes accompanying the SST increase. Despite very different precipitation values and convective organizations, the response to warming is similar for all shears: the fractional increase in precipitation extremes converges at the highest percentiles, to a value of about $10 \%-12 \%$ for Shear 0 and 

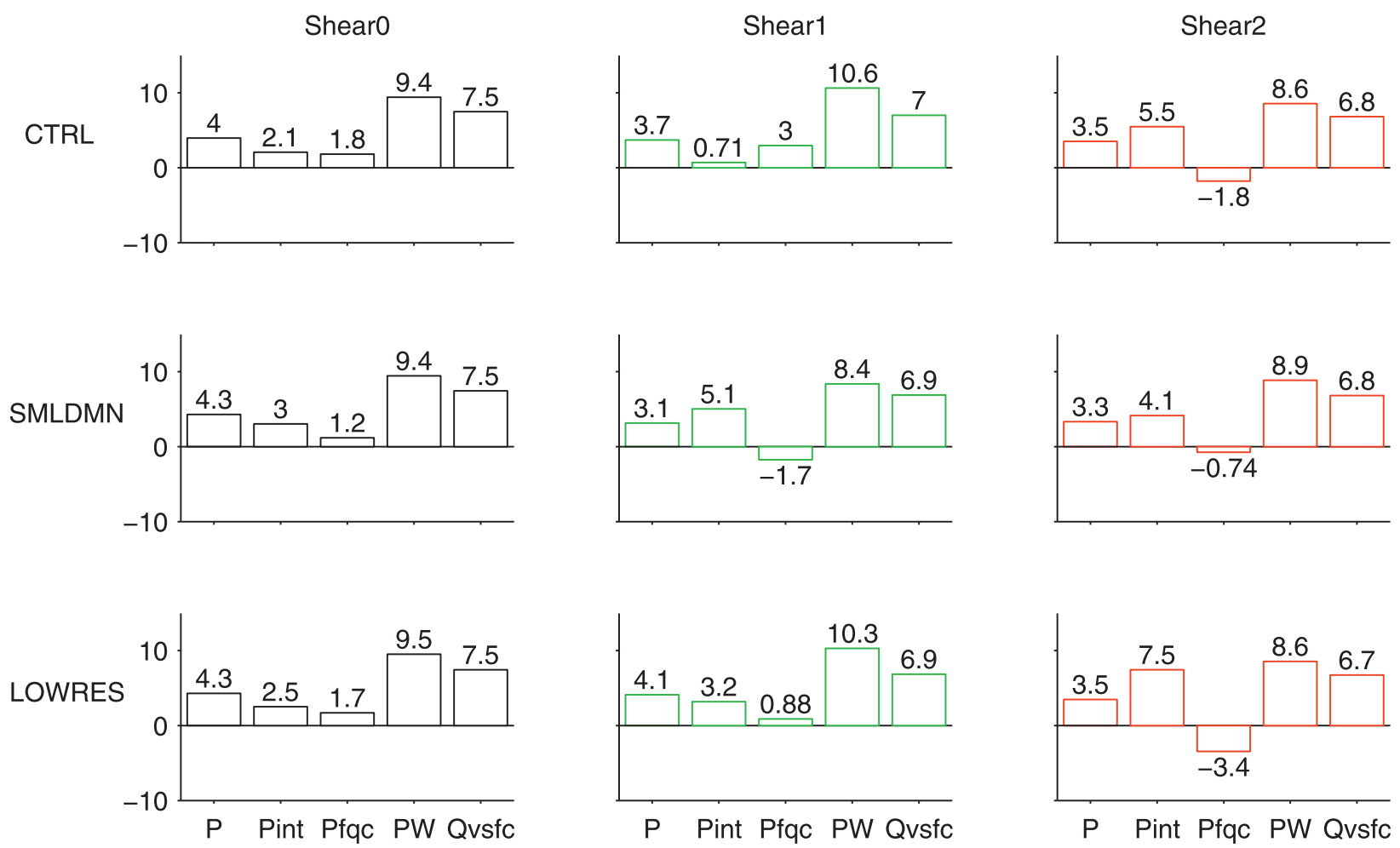

FIG. 6. Changes in time-domain averages $\left(\% \mathrm{~K}^{-1}\right)$ of mean precipitation, precipitation intensity, precipitation frequency, precipitable water, and near-surface specific humidity (first model level $z=37.5 \mathrm{~m}$ ) in the three shear cases (see Table 1 for a description of the runs).

Shear1 at the 99.99th precipitation percentile, and to a higher value of about $15 \%$ for Shear2.

A similar computation can be done in all of the casesCTRL, SMLDMN, and LOWRES - and the results are summarized in Fig. 9. The changes in atmospheric precipitable water $(\mathrm{PW})$ and in near-surface $\left(q_{v s f c}\right)$ water vapor are also shown as gray lines for reference $\left(\mathrm{CC}\right.$ and $\mathrm{CC}_{\mathrm{sfc}}$ scalings, respectively). We see that the exact value of the fractional increase in precipitation extremes is somewhat sensitive to the domain size and resolution, but there are several robust features. First, in all cases and shears, the increase in precipitation extremes is significantly smaller than the increase in atmospheric humidity. Second, despite the very different convective organizations without shear and with critical shear (Figs. 3 and 4), the response of precipitation extremes to warming is surprisingly similar, with a rate of increase much smaller than $\mathrm{CC}$ and even slightly smaller than $\mathrm{CC}_{\mathrm{sfc}}$. Third, the extremes have a stronger response to warming with supercritical shear. Extremes can increase at a rate close to or even above $\mathrm{CC}_{\text {sfc }}$.

Our results without shear are consistent with MOB11, who find that in disorganized convection the fractional increases in precipitation extremes are substantially less than the fractional increases in column water vapor, and are comparable in magnitude to (and slightly smaller than) those in surface water vapor concentrations (see their Fig. 4). But, our results with organized convection are at odds with Singleton and Toumi (2013), who find greater fractional rates of increase than the amount of atmospheric water vapor in their simulated squall lines. As noted earlier, we interpret their result as being the consequence of the uniform vertical warming, which increases the atmospheric instability and hence likely overestimates vertical velocities in updrafts.

Singleton and Toumi (2013) also observe a change in the behavior of extremes at a SST of $24^{\circ} \mathrm{C}$, with larger rates of increase for SSTs above $24^{\circ} \mathrm{C}$. According to their Fig. 1, this SST corresponds to a transition between stationary squall lines (near-critical shear) and slanted squall lines (supercritical shear), which could explain the change in behavior of extremes. It is interesting that the response of extremes to warming is not monotonic with shear and is mainly sensitive to the strongest supercritical shear in our simulations. As we will see in the next section, this is related to the behavior of vertical velocities in updrafts, which respond differently to warming with critical and with supercritical shears. Singleton and Toumi also note that vertical velocities play a role in the superCC scalings that they observe. In the next section we use a simple expression to analyze further those results and examine the thermodynamic and dynamic contributions to the changes in precipitation extremes in our simulations. 


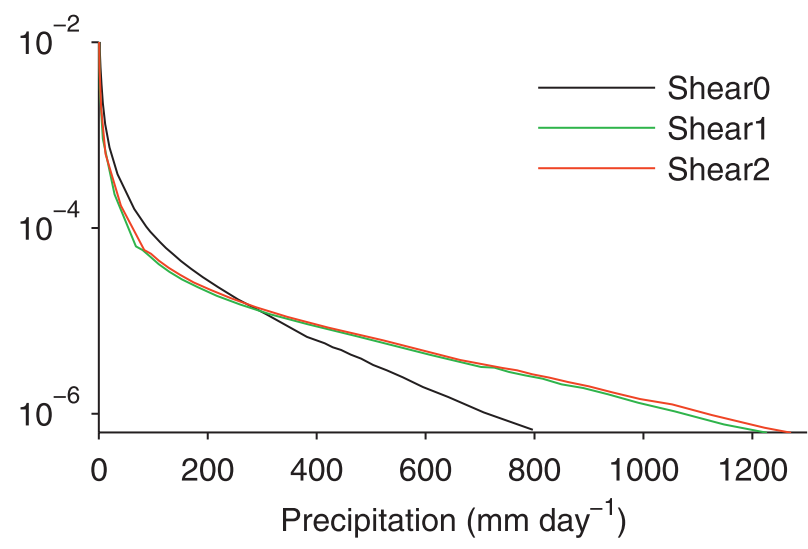

FIG. 7. Probability distribution function of hourly mean pointwise precipitation in CTRL (see Table 1 for details) with SST = $300 \mathrm{~K}$ for various shears.

\section{Scaling for changes in precipitation extremes}

\section{a. Scaling}

Our goal is to relate changes in precipitation extremes to changes in dynamical and thermodynamical variables. To that end, we use an approximate expression, or scaling, for the precipitation rate in an extreme precipitation event. Following MOB11, we use an energy rather than a water budget to derive the scaling because an energy budget allows us to more easily define a thermodynamical component (with no dependence on relative humidity) and also because the weak horizontal gradients of temperature in the tropics help to eliminate horizontal advective terms. From the vertically integrated dry static energy (DSE) budget of the model (Khairoutdinov and Randall 2003), it can be shown that the precipitation rate in an extreme event, $P_{e}$, is approximately given by (MOB11)

$$
P_{e}=\epsilon \frac{1}{L_{v}} \int \bar{\rho} w \frac{\partial\langle s\rangle}{\partial z}
$$

where $\epsilon$ denotes precipitation efficiency as defined in MOB11, $L_{v}$ is the latent heat of evaporation, $\bar{\rho}$ the reference density profile used in the anelastic governing equations, $w$ the resolved wind speeds along the Cartesian direction $z$, and $s=c_{p} T+g z$ is dry static energy; angle brackets represent the domain and time mean (over the whole length of the simulation once equilibrium is reached), and the integral is given by

$$
\int(\ldots)=\int_{900 \mathrm{hPa}}^{150 \mathrm{hPa}}(\ldots) d z \text {. }
$$

In the derivation of the scaling (2), horizontal advection and time derivatives have been neglected. These
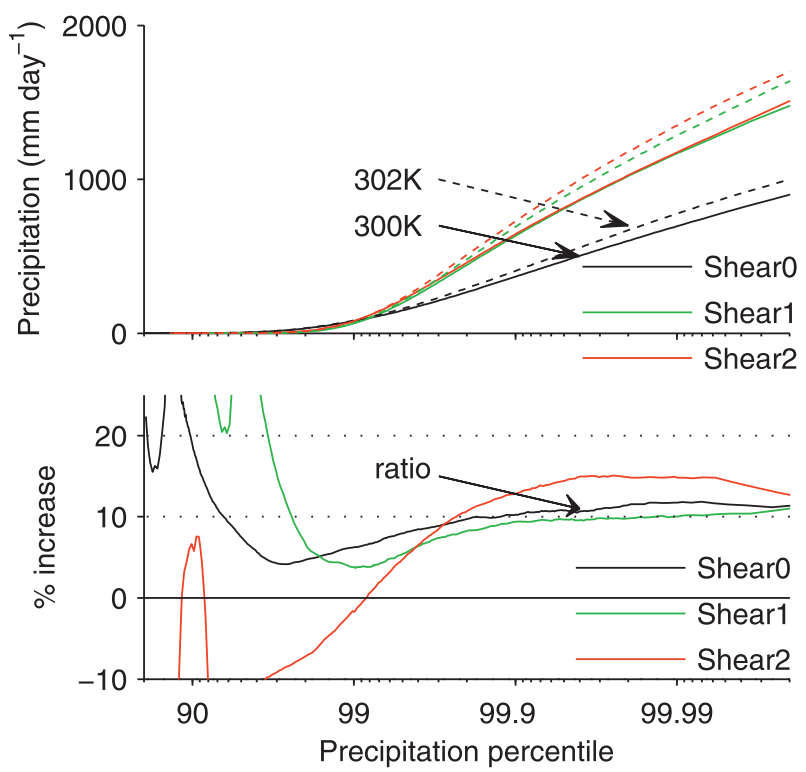

FIG. 8. Changes in the distribution of hourly mean pointwise precipitation extremes accompanying a $2-\mathrm{K}$ SST increase in the CTRL case (see Table 1 for details) for the three shears. (top) The values of precipitation $\left(\mathrm{mm} \mathrm{day}^{-1}\right)$ vs percentiles in the cold and warm simulations and (bottom) the fractional (\%) increase in rainfall rates between those two runs.

simplifications occur because of the strong upward motions associated with precipitation extremes and the weak horizontal gradients of temperature in the tropics so that the total time derivative of dry static energy is well approximated by the vertical advection term. Note that this scaling is similar but not identical to the one used in MOB11 in two ways. First, the integration bounds are not exactly the same. The lower and upper boundaries for the vertical integral are introduced to exclude the subcloud layer (see the mean profiles of nonprecipitating condensates in Fig. 10) and top layers of the model where damping is applied to avoid gravity wave reflection and buildup: we conducted the same analysis changing the lower and upper boundaries by $\pm 50 \mathrm{hPa}$ and found that our results are not sensitive to those values. Second, MOB11 use the fact that the mean atmospheric lapse rate is close to moist adiabatic in the model above the boundary layer (i.e., $d s \approx-L_{v} d q_{\text {sat }}$ ) to express the scaling (2) in terms of the saturation specific humidity from the mean temperature $q_{\text {sat }}(\langle T\rangle)$ instead of mean dry static energy $\langle s\rangle$. This makes the interpretation of the scaling easier since

$$
\epsilon \int \bar{\rho} w \frac{-\partial q_{\mathrm{sat}}(\langle T\rangle)}{\partial z}
$$

is simply the precipitation efficiency times the net condensation in the atmospheric column, including 

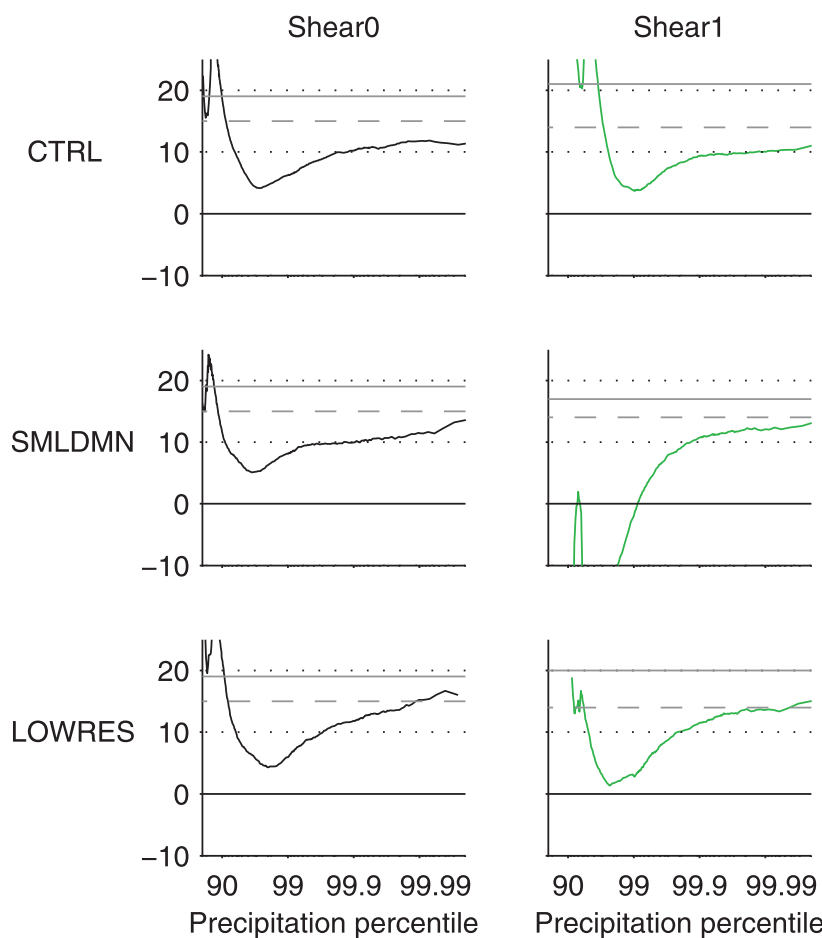

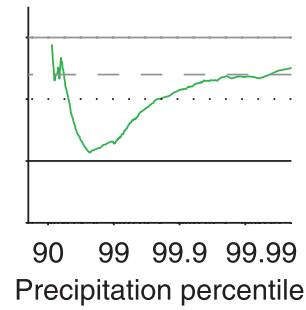

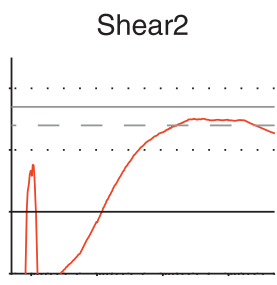
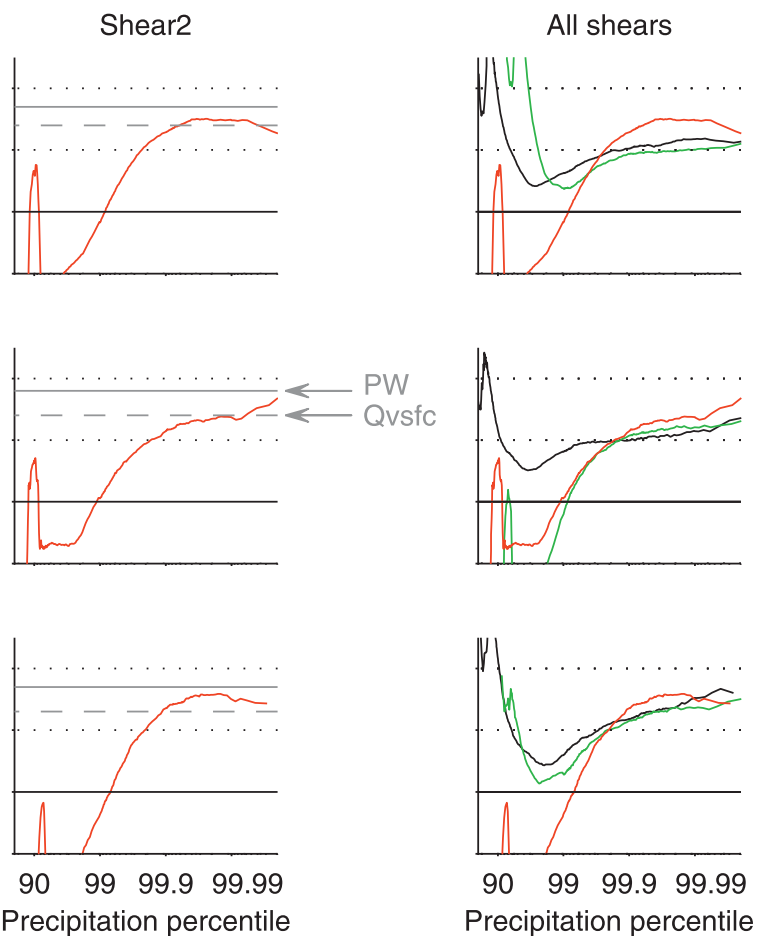

FIG. 9. Changes in the distribution of hourly mean pointwise precipitation extremes (\% increase) accompanying a 2-K SST increase for the CTRL, SMLDMN, and LOWRES cases (see Table 1 for details) and the three shear conditions. The changes in precipitable water and near-surface specific humidity are shown as gray solid and dashed lines, respectively. To ease comparison, the curves for various shears are superimposed on the right panels.

condensation from upward motion as well as evaporation of condensates from downward motion, maintaining a moist adiabatic lapse rate. As in the derivation of (2), horizontal advection and time derivatives have been neglected. We do not take this extra step because we find that, with shear, the agreement with precipitation extremes is better when we use the mean dry static energy, although the qualitative results are unchanged when using saturation specific humidity. We will come back to the interpretation of the scaling and its relationship to water vapor in section $5 \mathrm{c}$.

If changes in the precipitation efficiency are neglected, then from (2) fractional changes in $P_{e}$ are given by the scaling relation:

$$
\frac{\delta P_{e}}{P_{e}} \approx \frac{\delta \int \bar{\rho} w(\partial\langle s\rangle / \partial z)}{\int \bar{\rho} w(\partial\langle s\rangle / \partial z)} .
$$

The fractional changes in the scaling (3) with various shears in the CTRL case are shown in the middle panel of Fig. 11. The other cases (SMLDMN and LOWRES) look similar. In fact, all of the results discussed here and in the following sections hold in all the cases: therefore, from now on, we only show results for the CTRL case.
To ease comparison, we repeated the precipitation extremes changes from Fig. 9 in the left panel of Fig. 11. We see that the scaling captures the magnitude of the rate of increase of precipitation extremes with warming, as well as its sensitivity to shear: the amplification of extremes is similar without shear and with critical shear and is larger with supercritical shear. In the next section, we use the scaling (3) to evaluate the thermodynamic and dynamic contributions to precipitation extremes changes.

\section{b. Thermodynamic and dynamic contributions}

We can further decompose the scaling into two components, a thermodynamic component involving the change in dry static stability $\delta(\partial\langle s\rangle / \partial z)$ and a dynamic component involving the change in upward mass flux $\delta \bar{\rho} w$ (neglecting second-order terms):

$$
\delta\left(\int \bar{\rho} w \frac{\partial\langle s\rangle}{\partial z}\right) \approx \int \bar{\rho} w \delta\left(\frac{\partial\langle s\rangle}{\partial z}\right)+\int \delta(\bar{\rho} w) \frac{\partial\langle s\rangle}{\partial z} .
$$

The right panel of Fig. 11 shows the thermodynamical and dynamical contributions to the scaling. We see that to first order the rate of increase of precipitation extremes has the same magnitude as the thermodynamical scaling, which has a similar value for all shears, smaller than $\mathrm{CC}$ and close to $\mathrm{CC}_{\mathrm{sfc}} \approx 6 \%-7 \% \mathrm{~K}^{-1}$. This value is 


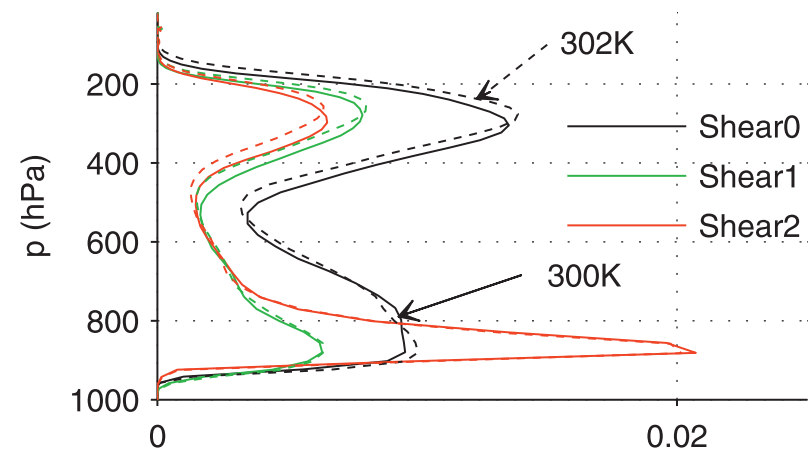

FIG. 10. Vertical profiles of nonprecipitating condensate (i.e., cloud) amounts $\left(\mathrm{g} \mathrm{kg}^{-1}\right)$ in CTRL, domain and time averaged, for the three shear conditions.

consistent with the mean fractional increase of dry static stability $\partial\langle s\rangle / \partial z$ averaged over the cloudy layers (900$150 \mathrm{hPa}$ in Fig. 10) on a theoretical moist adiabat when the SST is increased from 300 to $302 \mathrm{~K}$ : see also the values given by Betts and Harshvardhan (1987). The dynamical contribution, on the other hand, is not the same for all shears. It is small compared to the thermodynamical scaling, but it can vary greatly with shear. In fact, Fig. 11 makes clear that the larger amplifications of extremes with supercritical shear are due to positive dynamical contributions, as opposed to negative dynamical contributions without shear and with critical shear.

That the dynamical contribution is small compared to the thermodynamical contribution is consistent with results from Parodi and Emanuel (2009). Their idealized simulations suggest that, in radiative-convective equilibrium, extremes of vertical velocity in clouds scale with the fall speed of precipitation. Direct comparison with this theory is not straightforward since, unlike the simulations of Parodi and Emanuel, we do not use a constant fall speed independent of the precipitation size distribution. Nevertheless, according to this theory, one would indeed expect a small dynamical contribution to changes in rainfall rates.

To summarize these results, to first order the changes in precipitation extremes are captured by changes in the mean temperature structure of the atmosphere. This thermodynamical contribution is robust for all shears and is close to $\mathrm{CC}_{\text {sfc }} \approx 6 \%-7 \% \mathrm{~K}^{-1}$, which is significantly smaller than the change in atmospheric water vapor $\mathrm{CC} \approx 9 \%-10 \% \mathrm{~K}^{-1}$. Changes in convective mass fluxes play a secondary role and are not robust to shear. They tend to weaken the strength of precipitation extremes without shear and with critical shear, while they tend to increase the strength of precipitation extremes with supercritical shear.

\section{c. Relationship to water vapor}

To clarify the relationship between the scaling (3) and near-surface water vapor, we derive an even simpler scaling for the changes in precipitation extremes. While not as accurate as (3), it helps explain why changes in precipitation extremes follow $\mathrm{CC}_{\mathrm{sfc}}$. Since the tropical atmosphere is close to a moist adiabat, that is, $d s \approx$ $-L_{v} d q_{\mathrm{sat}}$, and since changes in relative humidity tend to be small, that is, $\delta\left(\partial q_{\mathrm{sat}} / \partial z\right) \approx \delta\left(\partial q_{v} / \partial z\right)$, where $q_{v}$ denotes water vapor specific humidity), it follows from (3) that

$$
\frac{\delta P_{e}}{P_{e}} \approx \frac{\delta \int \bar{\rho} w\left(-\partial\left\langle q_{v}\right\rangle / \partial z\right)}{\int \bar{\rho} w\left(-\partial\left\langle q_{v}\right\rangle / \partial z\right)} .
$$
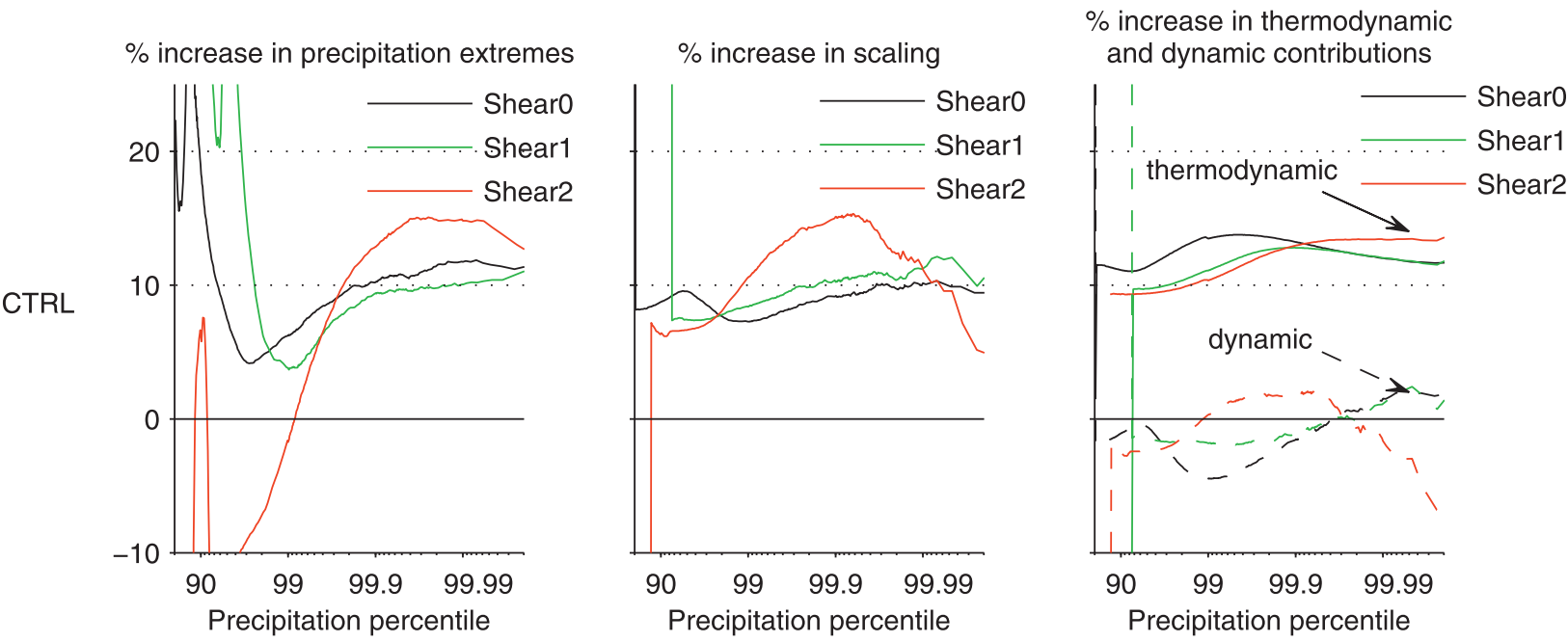

FIG. 11. Percent changes in (left) precipitation extremes, (middle) the scaling in (3), and (right) the dynamical and thermodynamical parts of the scaling in the CTRL case. 

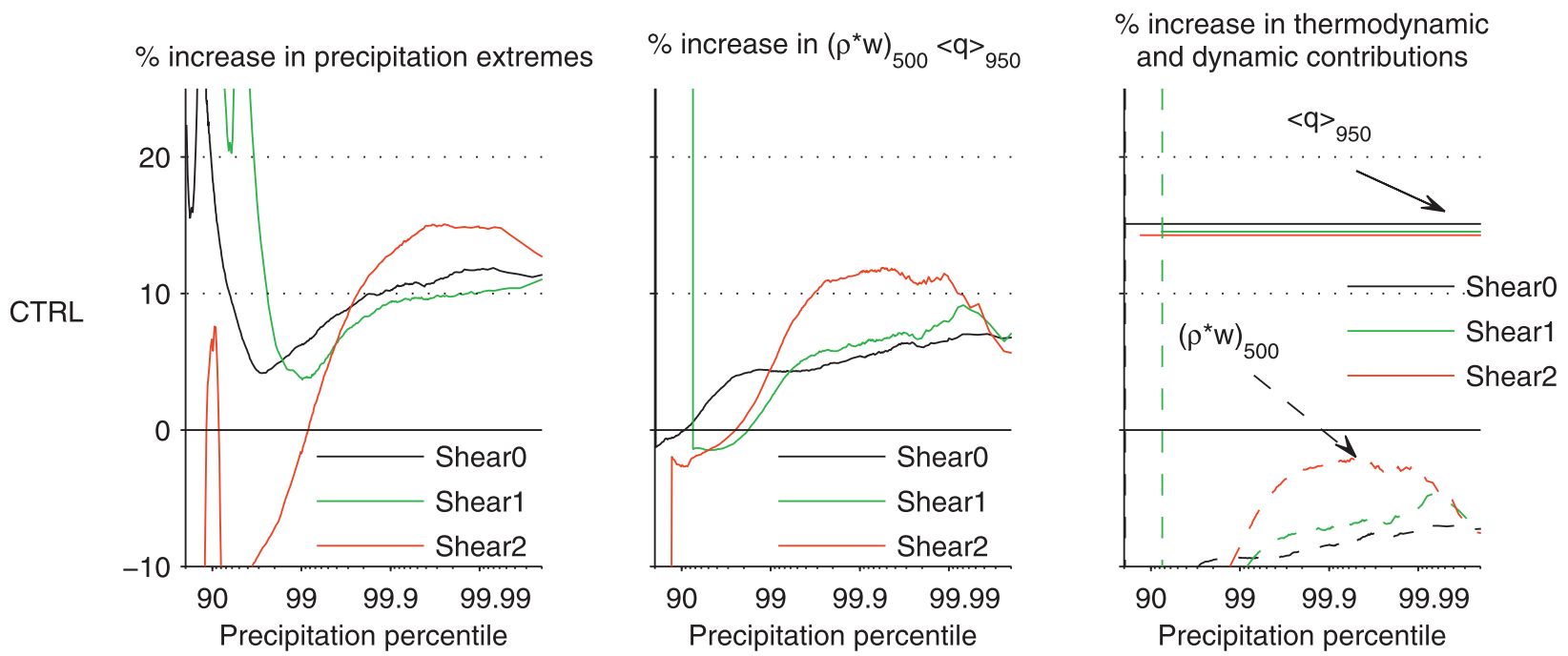

FIG. 12. As in Fig. 11 but the middle and right panels show changes in the rough estimate (7) $(\rho w)_{500}\left\langle q_{v}\right\rangle_{\mathrm{BL}}$ (angle brackets denote time and spatial mean). Its thermodynamical part is $\delta\left\langle q_{v}\right\rangle_{\mathrm{BL}}$, and its dynamical part is $\delta(\rho w)_{500}$.

If we further assume that a representative value of $\bar{\rho} w$ is its value at $500 \mathrm{hPa}$ (around $6 \mathrm{~km}$ ), then a rough scaling would be

$$
\int \bar{\rho} w\left(-\frac{\partial\left\langle q_{v}\right\rangle}{\partial z}\right) \sim(\bar{\rho} w)_{500} \int-\frac{\partial\left\langle q_{v}\right\rangle}{\partial z}=(\bar{\rho} w)_{500}\left\langle q_{v}\right\rangle_{\mathrm{BL}}
$$

where the subscript BL refers to boundary layer values.

An alternative way to derive this scaling is to assume that, in areas with strong convection, the precipitation is equal to the total water vapor horizontal convergence in the boundary layer:

$$
P_{e} \sim \nabla_{h}\left(\bar{\rho} u_{h}\right)_{\mathrm{BL}}\left\langle q_{v}\right\rangle_{\mathrm{BL}}
$$

From mass conservation, the horizontal convergence in the boundary layer is equal to the vertical mass flux in the convective updraft $\nabla_{h}\left(\bar{\rho} u_{h}\right)_{\mathrm{BL}} \approx(\bar{\rho} w)_{500}$, so precipitation extremes scale with

$$
P_{e} \sim(\bar{\rho} w)_{500}\left\langle q_{v}\right\rangle_{\mathrm{BL}}
$$

The fractional changes in the scaling (7) are shown in the middle panel of Fig. 12, and the thermodynamical and dynamical contributions $\left(\delta\left\langle q_{v}\right\rangle_{\mathrm{BL}} /\left\langle q_{v}\right\rangle_{\mathrm{BL}}\right.$ and $\delta(\bar{\rho} w)_{500} /$ $(\bar{\rho} w)_{500}$, respectively) are shown in the right panel. While not as accurate as (3), this rough scaling captures the general behavior of precipitation with warming. To leading order, the magnitude of the amplification of extremes with warming scales with boundary layer water vapor, and is robust throughout all cases and shears. Changes in convective mass fluxes play a secondary role and, unlike the earlier dynamical contributions in (4), they tend to weaken precipitation extremes for all shears. The weakening is stronger without shear and with critical shear than it is with supercritical shear, which explains the larger rates of increase of (7) with supercritical shear.

The top panels of Fig. 13 show the vertical profiles of mass flux at the 99.95th precipitation percentile in the control case for the various shears (the other cases look similar). ${ }^{1}$ Consistent with the dynamical contributions described earlier, we see that the decrease in vertical mass fluxes with critical and zero shear is not observed with supercritical shear. The decrease in vertical mass flux with zero shear is not inconsistent with Romps (2011) and MOB11, who find an increase in updraft velocities with warming in disorganized convection. Figure 13 shows that the decrease in convective mass flux occurs despite an increase in the maximum updraft velocity (bottom panels). The former is more relevant to precipitation extremes.

It is unclear why the decrease in mass flux at high precipitation percentiles does not occur in the presence of supercritical shear. Note that the change in mean mass flux $M$, which can be estimated from the mean precipitation and near-surface specific humidity changes (shown in Fig. 6) $\delta M / M \approx \delta P / P-\delta q_{v s f c} / q_{v s f c}$ (Betts 1998; Held

\footnotetext{
${ }^{1}$ As for precipitation extremes, we checked the convergence of statistics by splitting the time series in two and comparing results obtained in the two subsamples. We find that the vertical profiles, as well as differences between warm and cold simulations, are statistically significant.
} 

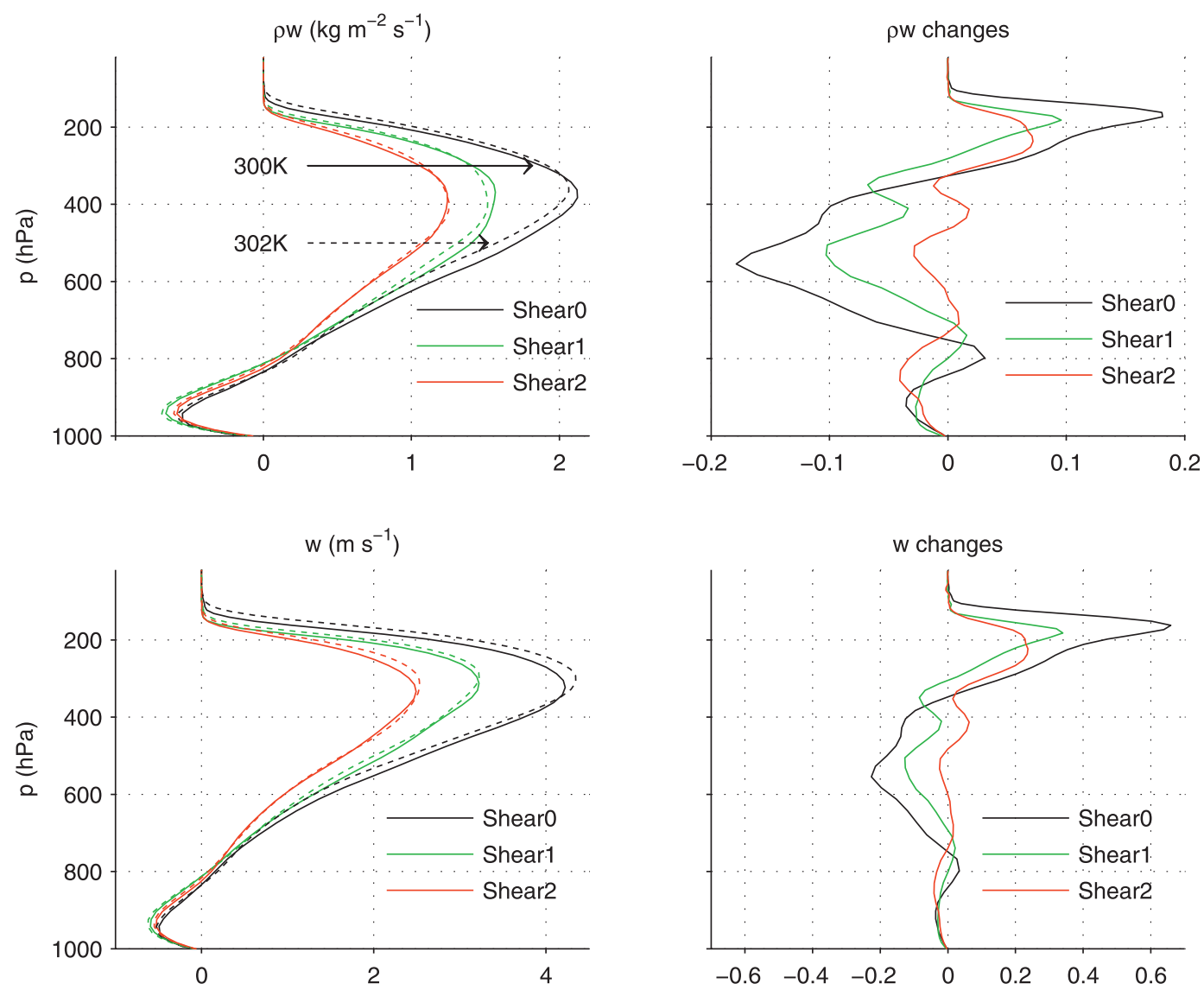

FIG. 13. Vertical (top) mass flux $\rho w$ and (bottom) velocities $w$ in the control case at the 99.95th percentile of precipitation for various shears. The values are shown in the left panels, and the changes between the cold and warm runs are shown in the right panels.

and Soden 2006), is approximately the same for all cases and shears and decreases at a rate of about $3 \%-4 \% \mathrm{~K}^{-1}$. The discrepancy between the decrease in mean convective mass flux, which is the same for all shears, and the decrease in convective mass flux at high precipitation percentiles, which does not occur with supercritical shear, may be related to the decrease in precipitation frequency with supercritical shear discussed in section 3 (less convective events with the same individual mass fluxes yield a smaller mean mass flux). Given its impact on precipitation extremes, more work is desirable to investigate in detail the distribution of convective mass flux and its response to warming.

\section{Conclusions}

Earlier studies of disorganized radiative-convective equilibrium found that the fractional rate of increase of precipitation extremes with warming was close to that of surface water vapor concentrations, or $\mathrm{CC}_{\text {sfc }}$ scaling, which is substantially less than the fractional increase in column water vapor, or CC scaling (Romps 2011; MOB11). Recent results from Singleton and Toumi (2013) indicate that changes in precipitation extremes could be significantly larger when the convection is organized.

Using vertical shear to organize the convection into squall lines, we examine the response of precipitation extremes to warming in a cloud-resolving model. Several shear profiles are investigated, namely no shear, critical shear, and supercritical shear, as well as various domain sizes and resolutions. We find that the exact value of the increase in precipitation extremes with warming is somewhat sensitive to resolution and domain size, but there are several robust features.

- Regardless of the strength of the shear, the fractional rate of increase of precipitation extremes with warming is comparable in magnitude to that of surface water vapor concentrations, which is significantly smaller than the increase in column water vapor.

- Despite very different convective organizations (cf. Figs. 3 and 4), the amplification of precipitation extremes without shear and with critical shear are surprisingly 
similar, with a rate of increase slightly smaller that $\mathrm{CC}_{\mathrm{sfc}}$. The dependence on shear is nonmonotonic, and extremes are more sensitive to supercritical shear, which yields increases close to or slightly above $\mathrm{CC}_{\text {sfc }}$.

- An approximate scaling is used to identify thermodynamic and dynamic contributions to precipitation extremes. We find that, for all shears, to first order the amplification of extremes is dominated by the thermodynamical component, which is close to $\mathrm{CC}_{\text {sfc }}$ and is related to changes in the mean temperature structure of the atmosphere. The dynamical contributions play a secondary role and differ for different shears: without shear and with critical shear the dynamical component tends to weaken extremes, while with supercritical shear it strengthens extremes.

The dynamical contribution is small but is responsible for the different behavior with different shears. This is caused by different responses of convective mass fluxes in individual updrafts: the decrease in mass fluxes at high precipitation percentiles with warming observed with zero and critical shear is not observed with supercritical shear (note that mass fluxes decrease with warming despite an intensification of maximum updraft velocities).

This is consistent with MOB11, who find that without organization, the changes in precipitation extremes are closer to (and slightly below) $\mathrm{CC}_{\text {sfc }}$ than to $\mathrm{CC}$, and are captured to first order by changes in the mean temperature structure of the atmosphere. They also find that changes in vertical velocities play a secondary role and tend to weaken the strength of precipitation extremes, despite an intensification of updraft velocities in the upper troposphere. But with organization, our results are at odds with Singleton and Toumi (2013), who find precipitation extremes increases in excess of CC. We interpret their result as being the consequence of the uniform vertical warming, which increases the atmospheric instability and, hence, likely overestimates vertical velocities and mass fluxes in updrafts and thus precipitation extremes. Interestingly, Singleton and Toumi observe a change in behavior of precipitation extremes in their simulated squall line when the SST exceeds $24^{\circ} \mathrm{C}$. Our results indicate that this might be due to the fact that this SST corresponds to a transition between stationary squall lines (near-critical shear) and slanted squall lines (supercritical shear), which could explain the change of behavior of extremes.

In the tropics, using column water vapor as a proxy for the rate of change of precipitation extremes instead of surface humidity can lead to substantial overestimates. Although our setting was idealized (square, doubly periodic domain, fixed radiative cooling rates and SSTs, no large-scale forcing or orography), the methodology developed should also be applicable to less idealized simulations. More work is desirable to investigate whether changes in precipitation extremes larger than those in atmospheric water vapor are possible under more realistic conditions.

Acknowledgments. The author would like to thank Isaac Held and Steve Garner for useful discussions about this work, Andrew Singleton and Ralf Toumi for providing further details about their simulations, and Kerry Emanuel for critical reading of the manuscript. Financial support for this work under the U.S. Department of Energy Grant DE-SC0006841 is gratefully acknowledged.

\section{REFERENCES}

Allan, R. P., and B. J. Soden, 2008: Atmospheric warming and the amplification of precipitation extremes. Science, 321, 14811484.

Allen, M. R., and W. J. Ingram, 2002: Constraints on future changes in climate and the hydrologic cycle. Nature, 419, 224-232.

Betts, A. K., 1998: Climate-convection feedbacks: Some further issues. Climatic Change, 39, 35-38.

_ cloud liquid water feedback in climate models. J. Geophys. Res., 92, 8483-8485.

Bretherton, C. S., P. N. Blossey, and M. Khairoutdinov, 2005: An energy-balance analysis of deep convective self-aggregation above uniform SST. J. Atmos. Sci., 62, 4273-4292.

Emori, S., and S. J. Brown, 2005: Dynamic and thermodynamic changes in mean and extreme precipitation under changed climate. Geophys. Res. Lett., 32, L17706, doi:10.1029/ 2005GL023272.

Fovell, R. G., and Y. Ogura, 1988: Numerical simulation of a midlatitude squall line in two dimensions. J. Atmos. Sci., 45, 38463879.

Garner, S. T., and A. J. Thorpe, 1992: The development of organized convection in a simplified squall-line model. Quart. J. Roy. Meteor. Soc., 118, 101-124.

Hartmann, D. L., and K. Larson, 2002: An important constraint on tropical cloud-climate feedback. Geophys. Res. Lett., 29, 1951, doi:10.1029/2002GL015835.

Held, I. M., and B. J. Soden, 2006: Robust responses of the hydrological cycle to global warming. J. Climate, 19, 5686-5699.

, R. S. Hemler, and V. Ramaswamy, 1993: Radiative-convective equilibrium with explicit two-dimensional moist convection. J. Atmos. Sci., 50, 3909-3909.

Houze, R. A., Jr., 2004: Mesoscale convective systems. Rev. Geophys., 42, RG4003, doi:10.1029/2004RG000150.

_ , and A. K. Betts, 1981: Convection in GATE. Rev. Geophys. Space Phys., 19, 541-576.

Khairoutdinov, M. F., and D. A. Randall, 2003: Cloud-resolving modeling of the ARM summer 1997 IOP: Model formulation, results, uncertainties, and sensitivities. J. Atmos. Sci., 60, 607625.

Kharin, V. V., F. W. Zwiers, X. Zhang, and G. C. Hegerl, 2007: Changes in temperature and precipitation extremes in the IPCC ensemble of global coupled model simulations. J. Climate, 20, 1419-1444. 
Lenderink, G., and E. van Meijgaard, 2008: Increase in hourly precipitation extremes beyond expectations from temperature changes. Nat. Geosci., 1, 511-514.

- , H. Y. Mok, T. C. Lee, and G. J. van Oldenborgh, 2011: Scaling and trends of hourly precipitation extremes in two different climate zones-Hong Kong and the Netherlands. Hydrol. Earth Syst. Sci., 15, 3033-3041.

Liu, S. C., C. Fu, C.-J. Shiu, J.-P. Chen, and F. Wu, 2009: Temperature dependence of global precipitation extremes. Geophys. Res. Lett., 36, L17702, doi:10.1029/2009GL040218.

Moncrieff, M. W., 2010: The multiscale organization of moist convection and the intersection of weather and climate. Why Does Climate Vary?, Geophys. Monogr., Vol. 189, Amer. Geophys. Union, 3-26.

Muller, C. J., and P. A. O'Gorman, 2011: An energetic perspective on the regional response of precipitation to climate change. Nat. Climate Change, 1, 266-271.

- , and I. M. Held, 2012: Detailed investigation of the selfaggregation of convection in cloud-resolving simulations. J. Atmos. Sci., 69, 2551-2565.

_, P. A. O'Gorman, and L. E. Back, 2011: Intensification of precipitation extremes with warming in a cloud-resolving model. J. Climate, 24, 2784-2800.

Nesbitt, S. W., E. J. Zipser, and D. J. Cecil, 2000: A census of precipitation features in the tropics using TRMM: Radar, ice scattering, and lightning observations. J. Climate, 13, 40874106.

O'Gorman, P. A., and T. Schneider, 2009: The physical basis for increases in precipitation extremes in simulations of 21stcentury climate change. Proc. Natl. Acad. Sci. USA, 106, $14773-14777$.

— - and C. J. Muller, 2010: How closely do changes in surface and column water vapor follow Clausius-Clapeyron scaling in climate change simulations? Environ. Res. Lett., 5, 025207 , doi:10.1088/1748-9326/5/2/025207.

Pall, P., M. R. Allen, and D. A. Stone, 2007: Testing the ClausiusClapeyron constraint on changes in extreme precipitation under $\mathrm{CO}_{2}$ warming. Climate Dyn., 28, 351-363.

Parodi, A., and K. A. Emanuel, 2009: A theory for buoyancy and velocity scales in deep moist convection. J. Atmos. Sci., 66, 3449-3463.
Robe, F. R., and K. A. Emanuel, 2001: The effect of vertical wind shear on radiative-convective equilibrium states. J. Atmos. Sci., 58, 1427-1445.

Romps, D. M., 2011: Response of tropical precipitation to global warming. J. Atmos. Sci., 68, 123-138.

Rotunno, R., J. B. Klemp, and M. L. Weisman, 1988: A theory for strong, long-lived squall lines. J. Atmos. Sci., 45, 463-464.

Singh, M. S., and P. A. O'Gorman, 2012: Upward shift of the atmospheric general circulation under global warming: Theory and simulations. J. Climate, 25, 8259-8276.

Singleton, A., and R. Toumi, 2013: Super-Clausius-Clapeyron scaling of rainfall in a model squall line. Quart. J. Roy. Meteor. Soc., 139, 334-339, doi:10.1002/qj.1919.

Soden, B. J., and I. M. Held, 2006: An assessment of climate feedbacks in coupled ocean-atmosphere models. J. Climate, 19, 3354-3360.

Stephens, G. L., S. Van Den Heever, and L. Pakula, 2008: Radiativeconvective feedbacks in idealized states of radiative-convective equilibrium. J. Atmos. Sci., 65, 3899-3916.

Sugiyama, M., H. Shiogama, and S. Emori, 2010: Precipitation extreme changes exceeding moisture content increases in MIROC and IPCC climate models. Proc. Natl. Acad. Sci. USA, 107, 571-575.

Tompkins, A. M., 2001: Organization of tropical convection in low vertical wind shears: The role of water vapor. J. Atmos. Sci., $\mathbf{5 8}, 529-545$.

Trenberth, K. E., 1999: Conceptual framework for changes of extremes of the hydrological cycle with climate change. Climatic Change, 42, 327-339.

- 2011: Changes in precipitation with climate change. Climate Res., 47, 123-138, doi:10.3354/cr00953.

Vecchi, G. A., and B. J. Soden, 2007: Global warming and the weakening of the tropical circulation. J. Climate, 20, 4316-4340.

WCRP, 1999: COARE-98: Proceedings of a Conference on the TOGA Coupled Ocean-Atmosphere Response Experiment (COARE). WCRP-107, WMO Tech. Doc. 940, 416 pp.

Weisman, M. L., and R. Rotunno, 2004: "A theory for strong longlived squall lines" revisited. J. Atmos. Sci., 61, 361-382.

Wilcox, E. M., and L. J. Donner, 2007: The frequency of extreme rain events in satellite rain-rate estimates and an atmospheric general circulation model. J. Climate, 20, 53-69. 